\title{
A LABORATORY APPROACH FOR DETERMINING EFFECTS OF POTENTIAL OIL SPILLAGE ON WATER QUALITY OF SUNDARBANS MANGROVE FOREST, BANGLADESH
}

\author{
H. Ara ${ }^{\mathrm{a}}$, M. S. Rahaman ${ }^{\mathrm{a}}$, M. M. Islam ${ }^{\mathrm{b}}$, A. Mallick ${ }^{\mathrm{c}}$ and M. S. Hossain ${ }^{\mathrm{c}}$ \\ ${ }^{a}$ Chemistry Discipline, Khulna University, Khulna 9208; ${ }^{b}$ Department of Chemistry, Bangladesh University of \\ Engineering and Technology, Dhaka; ${ }^{\mathrm{F}}$ Fisheries and Marine Resource Technology Discipline, Khulna University, \\ Khulna 9208, Bangladesh
}

\begin{abstract}
This study was conducted in laboratory as a microcosm approach in order to know the effect of oil (diesel) spillage on water quality of Sundarbans Mangrove Forest (SMF), Bangladesh. A series of laboratory tanks were filled with water of SMF with different concentrations of oils dispersed onto the waters. The water quality parameters viz. alkalinity, free $\mathrm{CO}_{2}$, dissolved oxygen, chemical oxygen demand, hardness, major anions (sulfate and chloride) and major cations $\left(\mathrm{Na}^{+}, \mathrm{K}^{+}, \mathrm{Ca}^{+2}\right.$ and $\left.\mathrm{Mg}^{+2}\right)$ were determined three times at nearly weekly intervals. Results indicate the degradation of oil followed by reduction of dissolved oxygen and evolution of free $\mathrm{CO}_{2}$, coupled with depletion of the concentration of $\mathrm{Ca}^{2+}$ and $\mathrm{Mg}^{2+}$ in tank waters. This might be due the complex formation of $\mathrm{Ca}^{2+}$ and $\mathrm{Mg}^{2+}$ with hydrocarbons which were insoluble in water. The water quality parameters of different laboratory tanks were also compared with those of different locations of SMF determined before the microcosm approach, suggesting that oil spillage deteriorates the water quality of SMF.
\end{abstract}

Key words: Water quality, simulation, oil spillage, Sundarbans Mangrove Forest (SRF)

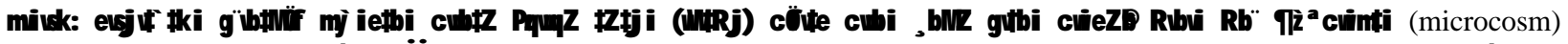

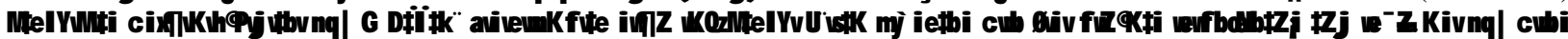

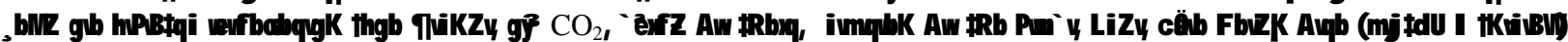

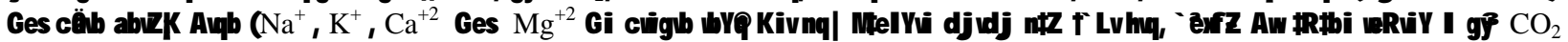

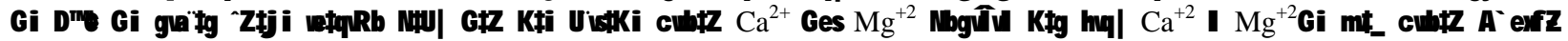

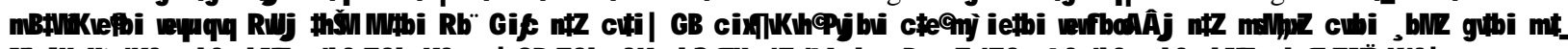

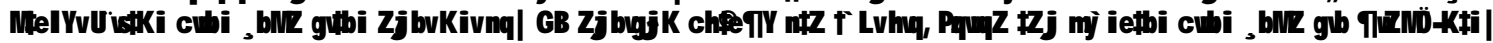

\section{Introduction}

The extensive shipping of crude oil over the world's oceans has increased concern about the effects of accidental spillage of petroleum in the marine environment. Increasingly large amounts of petroleum are entering the marine environment, primarily from three routs: natural seepage, offshore drilling and production, and transportation losses. However, major spills are associated with the increasing ocean transport of bulk liquids, particularly crude and refined petroleum products. Despite the importance and extent of mangrove ecosystems and their susceptibility and sensitivity to spilled oil, research on oil spills in mangroves ecosystem is still in its infancy with many key questions remaining unanswered (Getter et al. 1980).

The Sundarbans Mangrove Forest (SMF), the single largest chunk of productive mangrove forest in the world, plays an important role in the economy of the south western region of Bangladesh as well as in the national economy. Although there have been reports of frequent sighting of oil slicks in the maritime routes of
Mongla Port, there have not been systematic studies on the level of pollution caused by oil spills in our country. Nearly 500 sea going vessels are handled annually at Mongla Port which is located immediately upstream to the SMF. For navigation, the ships use the Passur River which passes through the forests. Moreover, numerous mechanized boats ply regularly inside the mangrove for different purposes. So, there is chance for the mangrove to be affected by oil pollution. Little studies on the magnitude of oil spills and their impact on the SMF have been conducted. Oil spills and indiscriminate discharge of bilge and bunker water from the ships and other vessels have frequently been reported to occur in Mongla Port (Siddiqi 2001). The most recent incident of oil spills due to ship wreckage occurred in 1994 when a cargo ship capsized near Dangmari forest station. Oil from the fuel tank spread over $15 \mathrm{~km}$ downstream from the ship and affected a considerable part of SMF. It was found to cause instant mortality of seedling of Heritiera fomes and Excoecaria agallocha, while patches of grasses covered by oil also died. Earlier on mortality of 
fishes, shrimps and other aquatic animals in the Sundarbans has been reported as a result of such incidence (Karim 1994). Monitoring and surveillance facilities are not available in Sundarbans to quantify the extent of oil pollution. No facilities exist for any clean up operation after an oil spill.

Tidal movements in the forests cause deposition of oil on mangrove roots, thus accumulating and penetrating in the soil. Two types of effects are observed over oil spills (Saenger et al. 1983). The first impact is immediate and acute. The second impact is long term chronic poisoning of mangrove plants and associated fauna by the toxic components of the retained oil. About $56-60 \%$ of the spilled oil over water surface is lost by evaporation depending on the type of oils. The light molecular weight fraction of oil gets dissolved in water and thus a dilute oil water suspension is formed, from which emulsification starts. The water content of the emulsion is about $8-20 \%$. It forms frothy mass. The consequent effect on water quality parameters include reduction of visibility (turbidity), reduction of photosynthesis, reduction in dissolved oxygen (imbalance in respiration and production), higher demands on nutrients (imbalance in nutrient budget), increase in the organic carbon content, and increase in oil and grease content (tainting effects on biota). In addition to this well accepted fate of oil spilling, there are also effects on the regulation of the chemical composition of water.

Keeping the abovementioned information in mind, an oil dispersion experiment was conducted at Karamjal Wildlife Breeding Centre and Mangrove Park under Chandpai range in August 2001 (JOECLA 2002). As a consequence of oil spillage, we hypothesize that there is effect on the ions regulation between water-sediment interfaces that were not possible to study at field levels because of large sensitive aquatic ecosystem. To test this hypothesis, we conducted a simulated response for oil spillage into the laboratory as a microcosm approach.

\section{Materials and Methods}

Sampling and analytical techniques: Water samples were collected in November 2004 from Dangmari station of SMF located adjacent to the Mongla Port, Khulna (Fig. 1). Salinity and $\mathrm{pH}$ of the water were measured in situ by Salinity Meter (AtagoRefractometer) and Hanna-pH Meter, respectively. Alkalinity, dissolved oxygen (DO), and free $\mathrm{CO}_{2}$ were determined by titrimetric method (APHA 1992). Water samples were transported into the Water Chemistry Laboratory, Fisheries and Marine Resource Technology Discipline, Khulna University, Khulna, and analyzed for different parameters. Water samples preserved with 1 $\mathrm{mL} \mathrm{HNO}_{3} / \mathrm{L}$ were analyzed for hardness and $\mathrm{Ca}^{2+}$ by EDTA titrimetric method from which $\mathrm{Mg}^{2+}$ was determined through calculation method (APHA 1992). While water samples preserved with $1 \mathrm{~mL} \mathrm{H}_{2} \mathrm{SO}_{4} / \mathrm{L}$ were analyzed for chemical oxygen demand (COD) by open-reflux titrimetric method (APHA 1992). $\mathrm{Na}^{+}$and $\mathrm{K}^{+}$were determined by flame photometry with a Jenway PF7 flame photometer. Such anionic species as $\mathrm{SO}_{4}{ }^{2-}$ and $\mathrm{Cl}^{-}$were determined by gravimetric method with drying residue and argentometric method, respectively (APHA 1992).

Laboratory simulations: Oil dispersion studies were conducted in four glass made tanks numbered A, B, C, and D each with a surface area of 3.5 sqft (Fig. 2a). Each tank was filled with 24L SMF water. Then 3mL, $9 \mathrm{~mL}, 15 \mathrm{~mL}$, and $21 \mathrm{~mL}$ oil (Diesel) were added to each of the four tanks (Fig. 2b). After spilling oil, $\mathrm{pH}$, alkalinity, free $\mathrm{CO}_{2}, \mathrm{DO}$, hardness, $\mathrm{Ca}^{2+}, \mathrm{Mg}^{2+}, \mathrm{Na}^{+}, \mathrm{K}^{+}$, $\mathrm{SO}_{4}{ }^{2-}$ and $\mathrm{Cl}^{-}$of each tank were measured three times. The observed data were compared with those determined before spilling at nearly weekly intervals.

\section{Results and Discussion}

The mean water quality parameters of the water samples from SMF (control) and the simulated oil dispersion tanks are shown in Table 1 . The oil content of Dangmari station was found to be $6.8 \mathrm{mg} / \mathrm{L}$. Irrespective of the individual specific compound as proposed by Department of Environment of Bangladesh, the acceptable standard for oil is $10 \mathrm{mg} / \mathrm{L}$. The $\mathrm{pH}$ of simulated tank waters followed a temporal (weekly) variation with high of 7.5 at first measurement and low of 6.3 in Tank- $\mathrm{D}_{3}$ where the spilled oil concentration was high. The range of free $\mathrm{CO}_{2}$ concentration in the simulated tanks varied between 13.2 to $22 \mathrm{mg} / \mathrm{L}$ whereas it was $8.8 \mathrm{mg} / \mathrm{L}$ in the control water. The DO concentration before oil spilling was 6.1 and after oil spilling into the tanks, the range varied from 5.8 to 2.2 $\mathrm{mg} / \mathrm{L}$. This could be attributed due to the reaction of DO with the hydrocarbons in oil and consequent evolution of free $\mathrm{CO}_{2}$. The alkalinity values ranged between 100 and $200 \mathrm{mgCO}_{3} / \mathrm{L}$. The ranges for major ions of the experimental waters in $\mathrm{mg} / \mathrm{L}$ were: $\mathrm{Na}^{+}$(1.88 to 1.70$)$, $\mathrm{K}^{+}$(8.14 to 8.07), $\mathrm{Ca}^{+2}$ (80.00 to 40.10$), \mathrm{Mg}^{+2}$ (111.13 to 
74.01), $\mathrm{Cl}^{-}$(1.43 to 1.22 ) and $\mathrm{SO}_{4}^{-2}$ (3.02 to 2.73). Since the highest $\mathrm{pH}$ of the study was 7.6, the phenolphthalein alkalinity was zero, that means the $\mathrm{CO}_{3}^{-2}$ concentration can be considered as zero. Variations of the above parameters with temporal and different tanks were minimal except for $\mathrm{Ca}^{+2}$ and $\mathrm{Mg}^{+2}$. Concentrations of $\mathrm{Ca}^{+2}$ and $\mathrm{Mg}^{+2}$ were depleted gradually and temporally from low concentrated spilled water (Tank $A_{1}$ ) to high concentrated one $\left(D_{3}\right)$. The temporal variation of average concentration of $\mathrm{DO}, \mathrm{CO}_{2}$ and $\mathrm{BOD}$ in different experimental tanks are shown in Fig. 3.

It is important to assess the effects of hydrocarbon spills on the regulation of chemical composition of natural waters. The resulting chemical composition is determined by entity of interacting chemical, physical, and biological factors which are intensity dependent. These intensive variables determine primarily the type of community of organisms present in the water (Stumn and Morgan 1984). Any change in chemical or physical variables will affect different species differently and thus will shift the species abundance (Patrick et al. 1954). But it is sometimes difficult to do this especially in large aquatic ecosystems. Laboratory assessment through simulation can be helpful to predict the consequence of chemical perturbation in aquatic ecosystems although it is not always possible to simulate the environmental conditions in laboratory as in aquatic ecosystems. But the reaction stoichiometry should be the same for laboratory and natural environment. So it could be predicted that the regulation of chemical composition is due to the effect of oil spillage. It is difficult to evaluate objectively and to codify water quality because of two reasons. First the effect of water composition on the various ecological consequences is little understood and very difficult to quantify and second, it is also difficult to define a reference state, i.e. a hypothetical pristine of the water.

The impact of a given oil discharge is determined very much by the nature of the hydrocarbons in the oil. Other factors including weather conditions and the distance of the discharge from shore also play an important role in determining the extent of ecological damage (Kerr 1977; Mielke 1990). The atmosphere contains a vast amount of oxygen, some of which can diffuse into the waters when they are under saturated. So when oils are dispersed onto the water there is less chance to incorporate the atmospheric oxygen into water and hence DO can be reduced. When oil is spilled onto the water surface, natural processes such as evaporation, dissolution and biodegradation play a large role in the fate of the oil spill. Ultimately most oil discharge get into an aquatic system and is degraded by a combination of biological, physical and chemical process, collectively referred to as weathering. Actual degradation rates depend on great many factors, including the characteristics of the oil, temperature, availability of nutrients, degree of physical mixing and so forth. The biodegradation is carried out by oxygen concentration reduction and free $\mathrm{CO}_{2}$ evaluation.

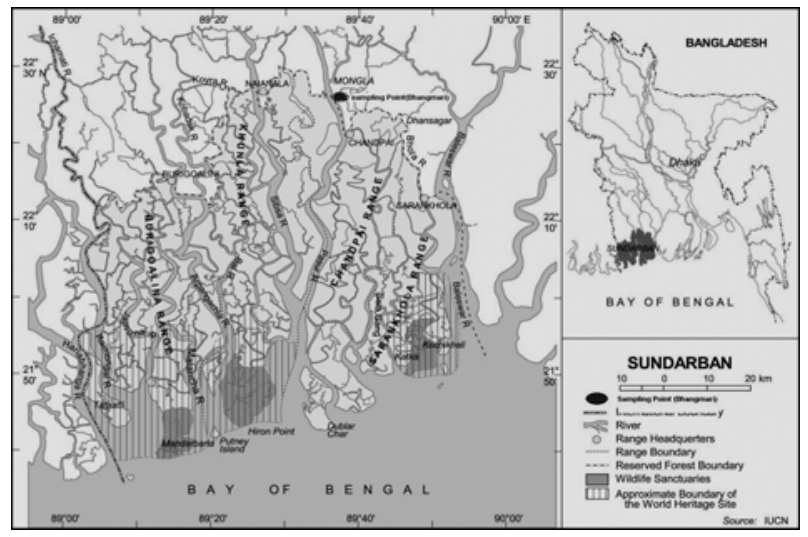

Fig.1. Site map of the Sundarbans Mangrove Forest (SMF)

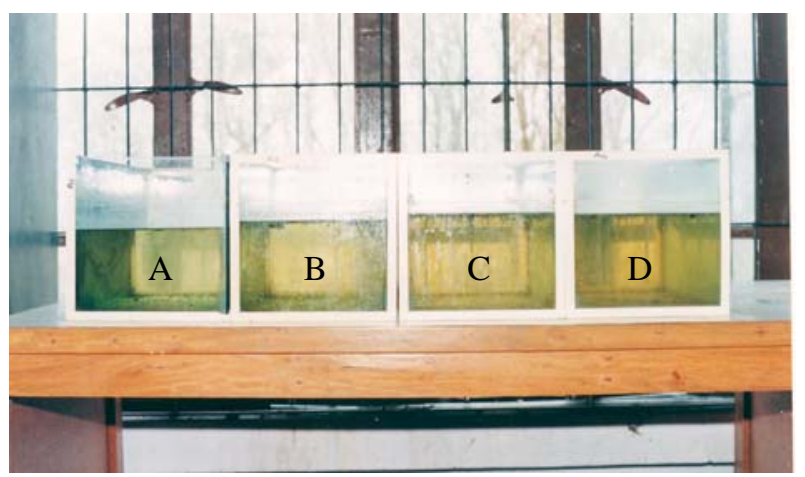

Fig. 2a. Glass tanks (A-D) arranged as microcosm for oil dispersion experiment

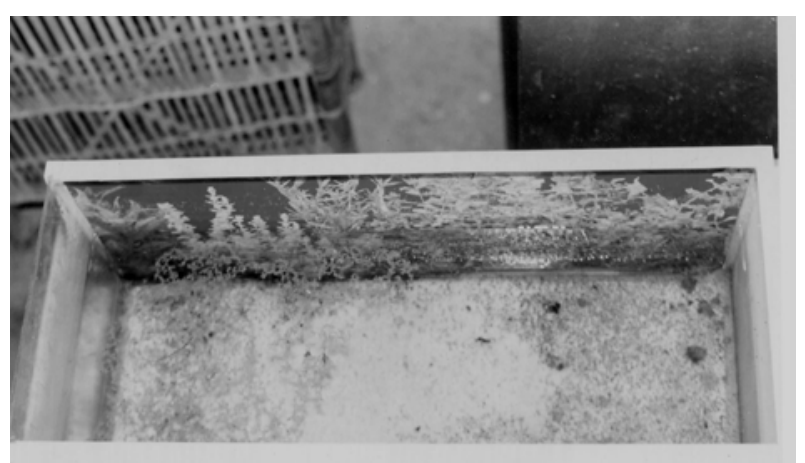

Fig. 2b. View of a tank after oil spillage onto its water 


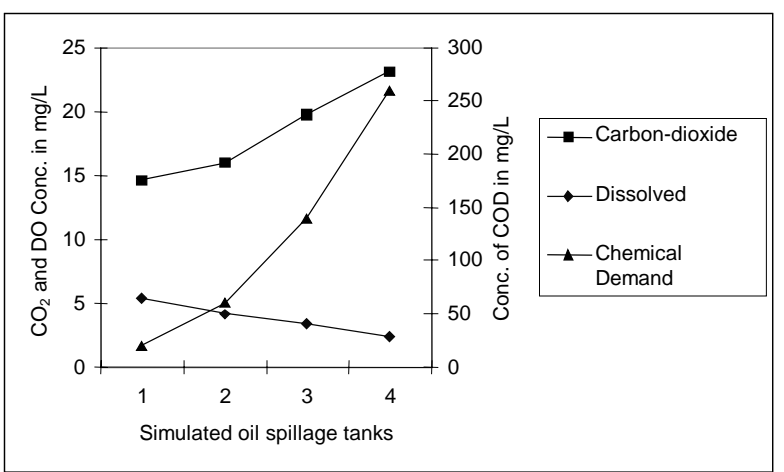

Fig. 3. Effect of oil spillage on dissolved oxygen (DO) concentration on simulated water tanks.

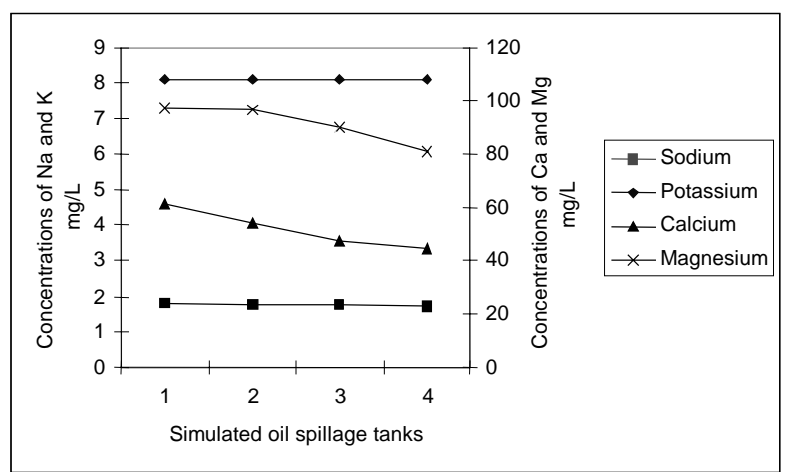

Fig. 4. Variation in concentrations of the major cations on simulated water tanks

Table 1. Water quality parameters before and after oil spills on SRF waters

\begin{tabular}{l|llllllllllll}
\hline & $\mathrm{pH}$ & $\mathrm{TA}$ & $\mathrm{CO}_{2}$ & $\mathrm{DO}$ & $\mathrm{COD}$ & $\mathrm{Hard}$ & $\mathrm{Na}^{+}$ & $\mathrm{K}^{+}$ & $\mathrm{Ca}^{+2}$ & $\mathrm{Mg}^{+2}$ & $\mathrm{Cl}^{-}$ & $\mathrm{SO}_{4}^{-2}$ \\
\hline D & 7.6 & $150 \pm 3.12$ & 4.7 & 6.1 & $31 \pm 2.8$ & $220 \pm 5.0$ & 1.88 & 8.14 & $80.0 \pm 5.12$ & 111.13 & $1.43 \pm 0.25$ & 3.01 \\
T-A1 & 7.5 & $100 \pm 1.63$ & 13.2 & 5.8 & $\mathrm{ND}$ & $200 \pm 5.0$ & 1.81 & 8.10 & $68.8 \pm 3.50$ & 103.12 & $1.22 \pm 0.21$ & 3.02 \\
T-A2 & 7.2 & $150 \pm 3.12$ & 13.2 & 5.2 & $\mathrm{ND}$ & $200 \pm 5.0$ & 1.78 & 8.10 & $61.3 \pm 3.50$ & 99.04 & $1.34 \pm 0.21$ & 2.93 \\
T-A3 & 7.0 & $150 \pm 3.12$ & 17.6 & 5.0 & $20 \pm 3.10$ & $190 \pm 3.5$ & 1.79 & 8.11 & $53.40 \pm 3.0$ & 90.18 & $1.33 \pm 0.21$ & 2.88 \\
T-B1 & 7.4 & $150 \pm 3.12$ & 14.8 & 4.3 & $\mathrm{ND}$ & $190 \pm 3.5$ & 1.80 & 8.12 & $57.3 \pm 3.12$ & 101.00 & $1.42 \pm 0.25$ & 2.91 \\
T-B2 & 7.0 & $150 \pm 3.12$ & 16.2 & 4.1 & $\mathrm{ND}$ & $190 \pm 3.5$ & 1.77 & 8.10 & $53.10 \pm 3.10$ & 97.00 & $1.40 \pm 0.25$ & 2.73 \\
T-B3 & 6.8 & $150 \pm 3.12$ & 17.0 & 4.0 & $60 \pm 5.0$ & $180 \pm 3.12$ & 1.74 & 8.10 & $52.1 \pm 3.10$ & 91.13 & $1.32 \pm 0.21$ & 2.81 \\
T-C1 & 7.4 & $150 \pm 3.12$ & 17.6 & 4.0 & $\mathrm{ND}$ & $180 \pm 3.12$ & 1.78 & 8.12 & $50.1 \pm 2.80$ & 94.19 & $1.23 \pm 0.21$ & 2.96 \\
T-C2 & 7.0 & $150 \pm 3.12$ & 20.6 & 3.2 & $\mathrm{ND}$ & $180 \pm 3.12$ & 1.78 & 8.10 & $49.2 \pm 2.80$ & 91.01 & $1.27 \pm 0.21$ & 2.91 \\
T-C3 & 6.6 & $200 \pm 3.96$ & 21.2 & 3.1 & $140 \pm 5.0$ & $180 \pm 3.12$ & 1.74 & 8.08 & $42.7 \pm 2.72$ & 85.10 & $1.23 \pm 0.21$ & 2.91 \\
T-D1 & 7.2 & $150 \pm 3.12$ & 22.0 & 2.6 & $\mathrm{ND}$ & $170 \pm 3.0$ & 1.71 & 8.09 & $49.5 \pm 2.80$ & 88.90 & $1.33 \pm 0.21$ & 2.98 \\
T-D2 & 6.9 & $200 \pm 3.96$ & 23.5 & 2.3 & $\mathrm{ND}$ & $170 \pm 3.00$ & 1.71 & 8.07 & $43.2 \pm 2.70$ & 80.17 & $1.31 \pm 0.21$ & 2.88 \\
T-D3 & 6.3 & $200 \pm 3.96$ & 23.9 & 2.2 & $260 \pm 7.5$ & $170 \pm 3.00$ & 1.70 & 8.08 & $40.1 \pm 2.72$ & 74.01 & $1.32 \pm 0.21$ & 2.81 \\
\hline
\end{tabular}

Note: D: Dangmari Station; \pm standard deviation; TA: Total Alkalinity in mg $\mathrm{CaCO}_{3} / \mathrm{L}$; Hard: Hardness in mg $\mathrm{CaCO}_{3} / \mathrm{L} ; \mathrm{CO}_{2}$, DO, COD, Na, K, Ca, Mg, Cl${ }^{-}$, and $\mathrm{SO}_{4}^{-2}$ in mg/L; ND: Not Detected; Tank-A1(104 ppm oil); Tank-B (311 ppm oil); Tank-C (519 ppm oil) and Tank-D (726ppm).

From this study it was found that when the concentration of oil content is increased the DO of the water was decreased with the subsequent release of free $\mathrm{CO}_{2}$ which supports the degradation of hydrocarbons by the end product of $\mathrm{CO}_{2}$. In many instances, the COD test is much more useful as a nonspecific analytical method even for estimating the oxygen requirements in polluted waters than in the BOD test. It is very valuable evaluation of wastes for which BOD test is not applicable due to the presence of toxic materials, low rate of oxidation or other similar factors. In this study COD values were increased due to the increasing concentration of hydrocarbons. The degradation process was slower and it happened through oxygen reduction due to the absence of enhanced biodegradation. Due to diesel spilling atmospheric air could be mixed with water, and sunlight could not be penetrated into water clearly. As a result, the photosynthesis process is hampered. Various observations had been made on critical as well as optimum levels of DO. Boyd (1978) stated that the minimum concentration of DO, tolerated by fish, was obviously a function of exposure time. A fish might survive in 0.5ppm DO for a few hours but not for several days. Further the minimum tolerable concentration of DO will be varying depending on the species and size of fish's physiological condition, 
concentrations of solutes and other factors. Eills (1989) indicated that under average conditions, 3.0ppm DO or less should be regarded as hazardous for fish. For a good variety of fauna, the DO level should be $5.0 \mathrm{ppm}$ or more. McKee and Wolf (1963) stated that the DO of warm water fish habitat should not be less than $5 \mathrm{ppm}$ for a period less than $8 \mathrm{~h}$ but at no time DO should be less than 3.0ppm.

Aquatic systems are particularly sensitive to many trace elements. The impact of trace elements on aquatic organisms depends on the chemical species of distribution. The factors that effect chemical speciation thus also influence the physiological and toxicological effects on organisms. Such as $\mathrm{pH}$, alkalinity, organic and inorganic ligands can influence the chemical speciation. Hydrocarbons can act as organic ligands which can complex with cations. In this study the depletion of $\mathrm{Ca}^{+2}$ and $\mathrm{Mg}^{+2}$ can be ascribed by complex formation.

From this work it was observed that the concentration of divalent cations $\mathrm{Ca}$ and $\mathrm{Mg}$ are depleted where as the variation of monovalent major cations were insignificant. This was due the, probably, the complex formation of divalent cations and hydrocarbons as organic ligands. These can be deposited onto the sediments. Consequently the required concentration of these metals can be reduced and hence can effect the physiological effects onto the organisms. For example, although it is clear that environmental calcium is beneficial in ameliorating the effects of environmental stressors, elevated calcium levels may offer no benefit when animal are reared under non stressful conditions( Seals et al. 1994). Moreover, when red drum are grown in fresh water, the water should contain a minimum of $25 \mathrm{mg} \mathrm{Ca}^{+2}$ and levels of $50-100 \mathrm{mg} / \mathrm{L}$, or more, are desirable for best survival, growth, and feed conversion efficiency (Wurts and Stickney 1989; Pursley and Wolters 1994). Organic compounds present in water often extent a pronounced influence on the inorganic constituents. Metal ions in waters often appear not to behave as predicted from the known chemistry of the metals in question. Frequently seawater shows an apparent supersaturation with respect to many inorganic compounds. The addition of organic compounds to water may increase or decrease biological activity, presumably because of increased or decrease rates of metal ion uptake by organisms. Conversely, the reactions of the organic substances present in water are influenced by the presence of metal ions. Despite these arrangements in favor of organic complexation very little direct proof for the existence of soluble chelates in natural waters is available. It is very difficult to detect soluble chelates in natural water by any direct method or to isolate them from natural water, especially with very small amounts of metal ions that are usually present. Concentrations of dissolved organic matter in natural water range from 0.1 to $10 \mathrm{mg} / \mathrm{l}$. The upper concentration is reached in lakes streams, and estuaries. Sediments are the principal depositories of posthumous organic debris and interstitial waters; in these dissolved organic matters may reach concentrations of up to 100mgC liter ${ }^{-1}$ and in a few instances of up to a few hundred mgC liter ${ }^{-1}$ (Brown et al. 1972).

\section{Conclusion}

Although Bangladesh has not yet experienced large-scale oil spill incidents, it is to be noted that the country has two international marine ports with potential oil spill risks. One of them is the Mongla Port, situated only $3 \mathrm{~km}$ north of the Sundarbans Reserved Forest (SRF) and is reached mainly by a $100 \mathrm{~km}$ long navigation channel through the Passur-Sibsa River system that runs through the SRF, implying that there is a possibility of deterioration of the aquatic environment due to oil spillage. It is apparent from this investigation that spillage might result in biodegradation of hydrocarbons and some forms of chemical reactions which in turn regulate the chemical composition of SMF. It is therefore necessary to monitor the changes in water quality status associated with oil spills. Moreover, to sustain the productivity of the natural environment, strategic plans need to be developed for the protection of the water environment from the harmful effects of any oil spills.

\section{References}

APHA 1992. Standard Methods of Water and Waste Water Analysis $\left(18^{\text {th }}\right.$ edn.). American Public Health Association, U.S.A.

Boyd CE. 1978. Water Quality in Warm water Fish Ponds. Agriculture Experimental Station, Auburn University. 359 pp.

Brown FS, Baedecker MJ, Kaplan IR, Nissenbaum, A. 1972. Geochim. Cosmochim. Acta 32: 397.

Eills KV. 1989. Surface Water Pollution and its Control. Macmillan Press Ltd., Hampshire. pp. 184-187 .

Getter CD, Nussman JM, Gundlach ER, Scott G.I. 1980. Biological Changes of Mangrove and Sand Beach Communities at the Peck Slip Oil Slip Site, Eastern Puerto Rico. National Oceanographic and Atmospheric Administration, Office of Marine Pollution Assessment, Boulder, CO. 63 pp. 
JOECLA 2002. Oil Spill Impact and Response Management Program. ADB TA No.

3357-BAN, Japan Oil Engineering Co. Ltd., Japan Oil Engineering Co., Ltd., Japan in Association with Fuyo Ocean Development \& Engineering Co., Ltd., Japan Consolidated Services Limited, Bangladesh.

Karim A. 1994. Environmental Impacts. In: Mangroves of the Sundarbans. Vol. two: Bangladesh (eds. Hussain, Z. and Acharya, G.), pp. 203-217, IUCN, Bankok.

Kerr RA. 1977. Oil in the ocean: Circumstances control its impact. Science 198: 1134-1136.

Mckee JE, Wolf HW. 1963. Water Quality Criteria (2nd edn.). Pub. No. 3-A, State Water Quality Control Board, The Resources Agency of California.

Mielke JE. 1990. Oil in the ocean: The Short- and Long-term Impacts of a Spill. Congressional Research Service Report for Congress. 24 pp.

Patrick RM, Hohn H, Wallace, JH. 1954. Proc. Natl. Acad. Sci., U.S.A, Vol-1, p. 259.
Pursely MG, Wolters WR. 1994. Effect of water hardness and chloride on survival, growth, and feed conversion of juvenile red drum Sciaenops ocellatus, J. World Aqua. Soc. 29: 67-73.

Saenger P, Hegerl EJ, Davie JDS. 1983. Global Status of Mangrove Ecosystems, Environmetalist 3(Suppl. 3): IUCN. 88 pp.

Seals C, Kempton CJ, Tomasso JR, Smith TR. 1994. Environmental calcium does not effect production or selected blood characteristics of sunshine bass reared under normal culture conditions. Progr. Fish-Culturist 56: 269-272.

Siddiqi NA. 2001. Mangrove Forestry in Bangladesh ( $1^{\text {st }}$ edn). Institute of Forestry and Environmental Science, University of Chittagong, Bangladesh.

Stumn W, Morgan JJ. 1981. Aquatic Chemistry: An Introduction to Emphasizing Chemical Equilibria in Natural Waters ( $2^{\text {nd }}$ edn.). John Wiley \& Sons, NewYork.

Wurts WA, Stickney RR. 1989. Responses of red drum (Sciaenops ocellatus) to calcium and magnesium concentrations in fresh and salt water. Aquacul. 61: 23-32. 